\title{
Ectopic adrenal tissue in adults
}

\author{
J. R. ANDERSON \\ F.R.C.S.
}

\author{
A. H. McLean Ross \\ F.R.C.S.
}

\section{Gastrointestinal Unit, Western General Hospital, Crewe Road, Edinburgh EH4 2XU}

\begin{abstract}
Summary
Two examples of ectopic adrenocortical tissue occurring in adults are presented. The embryological basis for this anomaly and is clinical significance are discussed.
\end{abstract}

\section{Introduction}

In 1740 Morgagni first described yellowish nodules resembling adrenal tissue adjacent to the main glands (Schechter, 1968). Since then, several accounts have been published locating ectopic adrenal tissue in various sites, most frequently in relation to the kidney (Mitchell and Angrist, 1943) or genital structures (Nelson, 1939; Falls, 1955). The clinical significance of these tissues is usually minimal but in certain situations they may be of importance. The authors wish to draw attention to this uncommonly encountered developmental anomaly, and report 2 cases in adults.

\section{Case report 1}

A 62-year-old woman was admitted with a 3-day history of central colicky abdominal pain, nausea and vomiting. On examination she was afebrile but had a tachycardia of $120 / \mathrm{min}$. Abdominal examination revealed tenderness and marked guarding in the right iliac fossa. Bowel sounds were diminished. Rectal examination was normal. A provisional diagnosis of acute appendicitis was made.

At laparotomy, an acutely inflamed appendix was found with a 1-cm diameter mass at its base. This mass was adherent to terminal ileum and mesovarium. The appendix was removed and the mass incised. The nodule was yellowish in colour and thought to be a carcinoid tumour. The grid-iron incision was extended and a right hemicolectomy and right salpingo-oöphorectomy carried out. The liver was palpably normal. Postoperatively the patient developed a wound infection but otherwisen made an uneventful recovery. She remains well 4.58 years later.

Histologically there was evidence of acute appendicitis. The mass was composed of adrenocortical tissue surrounded by acute inflammatory exudate. The right hemicolon, ovary and Fallopian tube were normal.

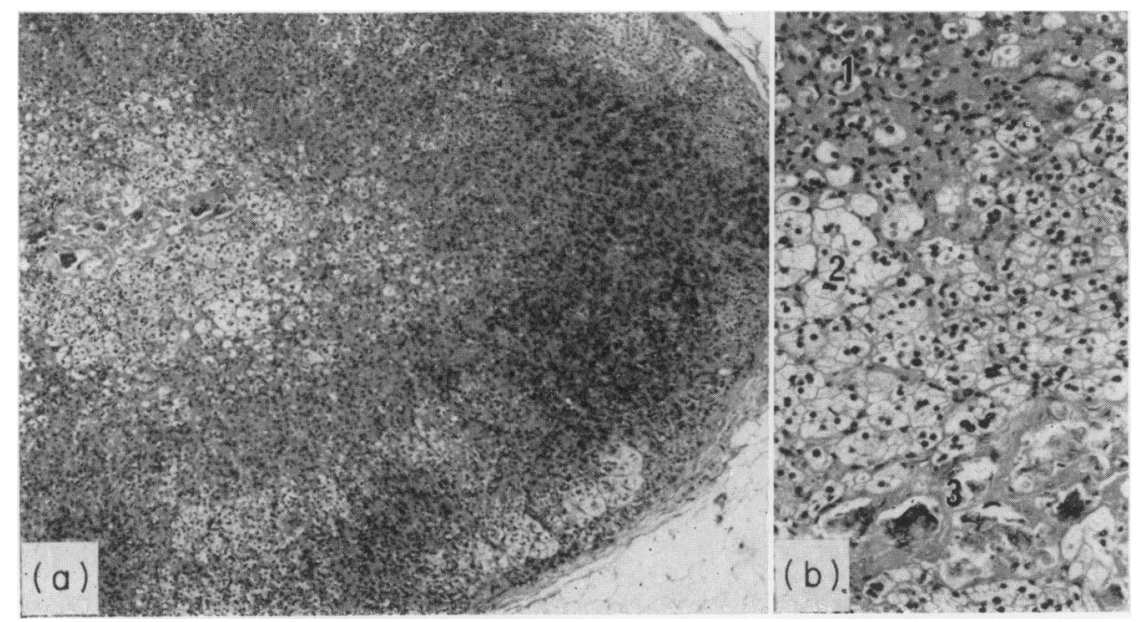

FIG. 1. Case 2: Photomicrograph (HE, $\times 55$ (a); $\times 135$ (b)) showing encapsulated ectopic adrenal (a) consisting of zona fasciculata-type cells mostly compact in type (b-1) but with occasional lipid laden clear cells (b-2). No medullary tissue is present but in the central area, there is focal calcification (b-3). 


\section{Case report 2}

A 53-year-old man presented to the out-patient clinic complaining of a mass in his right groin which he had first noticed about 4 months previously. It had not increased in size over this time. Examination revealed a small mobile oval mass in the right inguinal region, thought to be a lymph node.

Exploration of the area revealed a $1-\mathrm{cm}$ diameter yellowish-brown nodule within the inguinal canal without evidence of any hernia. Histologically this was composed of adrenocortical tissue (Fig. 1).

Neither patient showed any evidence of hormone imbalance pre- or postoperatively.

\section{Discussion}

Developmental anomalies of the adrenal gland are classified into heterotopias, renal-adrenal adherence and ectopic or accessory tissue. Embryologically the adrenal develops from 2 primordia of different origins. The cortex arises from the coelomic mesothelium and the medulla from neural crest ectoderm. During the 4th and 5th weeks of embryonic life, mesothelial cells from the angle between the root of the mesentery and the developing gonad proliferate, separate from the coelomic epithelium, and condense in the mesenchyme of the dorsal abdominal wall to form the primitive cortex. A second wave of cells from the same somatopleuric area is added to this at a slightly later date to form the definitive cortex, which persists into adult life. Cells from the neural crest ectoderm migrate to the medio-dorsal aspect of the primitive cortex and begin to invade it. Complete encapsulation of the medulla does not occur until late in fetal development.

True adrenal heterotopia is a rare condition and arises as a failure of separation of the developing cortex from the coelomic mesothelium, thus allowing it to become partly or wholly incorporated into adjacent organs. O'Crowley and Martland (1943) found 8 cases of complete or partial adrenal-renal heterotopia in 5000 post-mortems, and examples have been reported involving the liver (Weller, 1925).

Renal-adrenal adherence is a related condition in which the kidney and adrenal gland develop either in immediate contact without any capsule or with a single intervening capsule. Davie (1935) found 6 such cases in 1500 post-mortems.

Ectopic adrenal tissue probably develops either as multiple primordia or from fragments separated during invasion of the cortex by the medullary elements. Accessory glands situated close to their original position may contain medulla but the more distant, usually migrating with the developing genital gland, only have cortex (Falls, 1955). In 50\% of post-mortems on neonates and children accessory adrenal tissue can be found (Jaffe, 1927) but by adult life most of this tissue atrophies so that in only $1 \%$ can such tissue be found with ease (Mitchell and Angrist, 1943). Graham (1953), however, found adrenal tissue in the region of the coeliac axis in 32 of 100 consecutive adult cadavers and in 16 of these medullary tissue was also present.

Most examples of ectopic adrenal tissue are found incidentally. MacLennan (1919) examined the hernial sacs of 700 children and found nodules of adrenal tissue in 6 of them. Falls (1955) found 13 nodules in the broad ligaments of 11 women during a 14-month period (at laparotomy in 9 women and at post-mortem in the other 2) and suggested that these abnormalities are more common than previously reported. Pathological conditions may develop in this ectopic tissue similar to those seen in normally situated glands. Normann, Havnen and Mjolnerod (1971) reported a case of neuroblastoma in 2 ectopic glands in an 11-month-old child. Carcinomas have occasionally been reported (Schechter, 1968). Adenomatous hyperplasia can occur as an independent phenomenon or in association with similar changes in the adrenals proper. Compensatory functional hypertrophy after destruction or removal of normal adrenal glands has been reported, and may rarely account for relapse after adrenalectomy for breast cancer or Cushing's syndrome (Chaffee et al., 1963).

True heterotopic glands may be removed accidentally and this is most likely to occur during nephrectomy. Renal-adrenal adherence will also cause problems during nephrectomy if not recognized. David and Kardos (Schechter, 1968) reported a death from adrenal insufficiency following hepatic resection, the liver containing a heterotopic adrenal gland. Pengelly (1959) excised a phaeochromocytoma from within the renal capsule.

In the first case reported here, the ectopic tissue was located in the appendiceal mesentery close to the base of the appendix and this resulted in radical surgery being undertaken for what was thought to be a carcinoid tumour. Recognition of the nodule as adrenal tissue would prevent the necessity for such surgery. The position of the nodule in the second case is not uncommon for ectopic adrenal. The presentation at such a late stage in life is, however, difficult to explain in the absence of any endocrine imbalance.

\section{Acknowledgment}

We thank Mr J. A. Ross and Mr A. C. B. Dean for permission to report these cases. We also thank Dr A. Busuttil for his help regarding the pathology of these 2 cases.

\section{References}

Chaffee, W.R., Moses, A.M., Lloyd, C.W. \& Rogers, L.S. (1963) Cushing's syndrome with accessory adrenocortical tissue. Journal of the American Medical Association, 186, 799. 
Davie, T.B. (1935) Renal-adrenal adherence. British Journal of Surgery, 22, 428.

Falls, J.L. (1955) Accessory adrenal cortex in the broad ligament. Cancer, 8, 143.

Graham, L.S. (1953) Celiac accessory adrenal glands. Cancer, 6, 149.

Jaffe, H.L. (1927) The suprarenal gland. Archives of Pathology and Laboratory Medicine, 3, 414.

MACLENNAN, A. (1919) On the presence of adrenal rests in the walls of hernial sacs. Surgery, Gynecology and Obstetrics, 29, 387.

Mitchell, N. \& Angrist, A. (1943) Adrenal rests in the kidney. Archives of Pathology and Laboratory Medicine, 35, 46.
Nelson, A.A. (1939) Accessory adrenal cortical tissue. Archives of Pathology and Laboratory Medicine, 27, 955. ه

Normann, T., Havnen, J. \& Muolnerod, O. (1971) Cushing's C syndrome in an infant associated with neuroblastoma in two ectopic adrenal glands. Journal of Pediatric Surgery, 6, 169.

O'Crowley, C.R. \& Martland, H.S. (1943) Adrenal heterotopia, rests, and the so-called Grawitz tumor. Journal of Urology, 50, 756.

Pengelly, C.D. (1959) Phaeochromocytoma within the $\overparen{\mathbb{R}}$ renal capsule. British Medical Journal, 2, 477.

SCHECHTER, D.C. (1968) Aberrant adrenal tissue. Annals of Surgery, 167, 421.

Weller, C.V. (1925) Heterotopia of adrenal in liver and $\vec{\circ}$ kidney. American Journal of Medical Science, 169, 696. 